\title{
Low dose intraventricular fibrinolytic treatment to prevent posthaemorrhagic hydrocephalus
}

\author{
A Whitelaw, R P A Rivers, L Creighton, P Gaffney
}

\begin{abstract}
Posthaemorrhagic ventricular dilatation (PHVD) is thought to be due to clots from intraventricular haemorrhage obstructing cerebrospinal fluid pathways involved in reabsorption. Over $60 \%$ of infants with progressive PHVD have gone on to require surgical shunt placement. Previous treatments all have major problems. The object of this pilot study was to achieve enough fibrinolysis to restore pathways of cerebrospinal fluid reabsorption and so avoid shunt surgery. Nine preterm infants with progressive PHVD were treated with intraventricular infusion of streptokinase for 12-72 hours. All the infants survived and surgical shunting was required in only one case. A $\mathbf{2 0 0} \%$ increase in fibrinolytic activity was demonstrated in both ventricular and spinal fluid during streptokinase treatment. There were no cases of infection. Minor rebleeding occurred in one case and was not a serious problem. This represents the first direct therapeutic approach to the pathology of PHVD.
\end{abstract}

Posthaemorrhagic ventricular dilatation is one of the most serious complications of prematurity. It occurs after intraventricular haemorrhage and is assumed to be caused by small particles of blood clot obstructing the flow of cerebrospinal fluid through the ventricular system, basal cisterns, and arachnoid villi on the surface of the cerebral hemispheres. Subsequent chronic infiltration with collagen converts a potentially reversible hydrocephalus into a permanent one. ${ }^{1}$

Small sick infants are not suitable for shunt surgery because of high cerebrospinal fluid protein and poor pulmonary status and shunting later is associated with a high rate of blockage and infection. ${ }^{2}$ Repeated tapping of spinal or ventricular cerebrospinal fluid can temporarily reduce pressure and control head enlargement but there is a $7 \%$ risk of meningitis with repeated taps. ${ }^{3}$ Attempting to reduce cerebrospinal fluid production with acetazolamide produces metabolic acidosis in all infants and carbon dioxide retention in preterm infants with chronic lung disease. ${ }^{4}$ Hence there is a great need for alternative approaches to treatment of posthaemorrhagic hydrocephalus.

The use of urokinase for prevention of hydrocephalus after intraventricular haemorrhage was investigated in a controlled study in dogs by Pang et al. ${ }^{5}$ They showed that 20000 units of intraventricular urokinase every 12 hours significantly reduced hydrocephalus and cerebral damage after injection of blood into a lateral cerebral ventricle. Newman and Stewart described the use of intraventricular urokinase and streptokinase to activate plasminogen and so prevent hydrocephalus in 17 infants with meningitis. ${ }^{67}$ They used up to 25000 units of streptokinase per dose with no evidence of bleeding or inflammatory reaction. Todo et al described the intraventricular urokinase treatment of six adult patients with intraventricular haemorrhage. ${ }^{8}$ Intraventricular urokinase was started as soon as one day after onset of symptoms at a dose of $\mathbf{1 0} 000$ units twice a day. They concluded that shunt requirement and neurological disability were reduced when compared with historical controls. No rebleeding due to urokinase treatment was seen. In the light of these therapeutic possibilities, we have carried out a pilot study to determine whether the fibrinolytic agent, streptokinase, can be used to prevent permanent hydrocephalus and shunt dependence after intraventricular haemorrhage in preterm infants.

\section{Patients and methods}

The data from Newman and Stewart on the elimination of streptokinase from the cerebrospinal fluid suggested that a continuous infusion into a cerebral ventricle would be necessary to obtain an effect over a prolonged period of time. ${ }^{6}$ The table shows the characteristics of the nine infants who received a course of streptokinase. They ranged in gestational age from 25 to 31 weeks and in birth weight from $724 \mathrm{~g}$ to $1750 \mathrm{~g}$. Intraventricular haemorrhage had been diagnosed by ultrasound in all cases within 96 hours of birth and the ventricular width of each lateral ventricle had subsequently enlarged to 4 $\mathrm{mm}$ over the $97 \mathrm{th}$ centile for postmenstrual age. $^{3}$ Streptokinase treatment was started at a postnatal age ranging from 8 days to 27 days. One other infant with massive intraventricular haemorrhage was initially considered suitable for streptokinase treatment because of ventricular enlargement. Soon after insertion of the ventricular catheter it was discovered that the infant had a capsular haematoma of the liver and the streptokinase infusion was aborted. A blood sample taken at the time showed no evidence of a systemic streptokinase effect.

The treatment regimen consisted of intraventricular infusion of 20 000-25000 units of streptokinase/24 hours for 48 to 72 hours. The streptokinase (Streptase, Behringwerke or Kabikinase, $\mathrm{Kabi}$ ) was made up in $0.9 \%$ sodium chloride or $5 \%$ dextrose solution and given at $0.5 \mathrm{ml} /$ hour. The 20 gauge catheter (Ledercath, Vygon) was inserted through the lambdoid 
suture $1.5 \mathrm{~cm}$ lateral to the midline into the temporal horn of the larger of the lateral ventricles, using a needle and guidewire technique (figure). The catheter insertion was done under ultrasound imaging via the anterior fontanelle in three cases. After withdrawal of fluid to achieve a reduction in cerebrospinal fluid pressure, the continuous infusion of streptokinase was started. In infant 1 (table) a bolus of streptokinase (10 000 units) was given in $0.5 \mathrm{ml}$ before the infusion.

A lumbar puncture was carried out during the streptokinase infusion, withdrawing 10 or more ml of cerebrospinal fluid to help the streptokinase to spread through the ventricular system to the subarachnoid space. Intraventricular vancomycin $1 \mathrm{mg}$ was given at the start of the procedure and intravenous vancomycin was given for 72 hours as prophylaxis against infection. Twice daily ultrasound measurements were made of ventricular size and ventricular fluid was removed, if necessary, in order to maintain a low cerebrospinal fluid pressure (1-2 $\mathrm{mm} \mathrm{Hg}$ ) and so prevent any tendency for fluid to back-track around the catheter and escape under the transparent occlusion adhesive dressing. Two of the infants were treated at Hammersmith Hospital, London, two at Queen Charlotte's Hospital, London, two at Aker University Hospital, Oslo, two at Ullevål University Hospital, Oslo and one at St Mary's Hospital, London. The above procedure was approved by the Hammersmith and Queen Charlotte's research ethics committee and the research ethics committee of Oslo

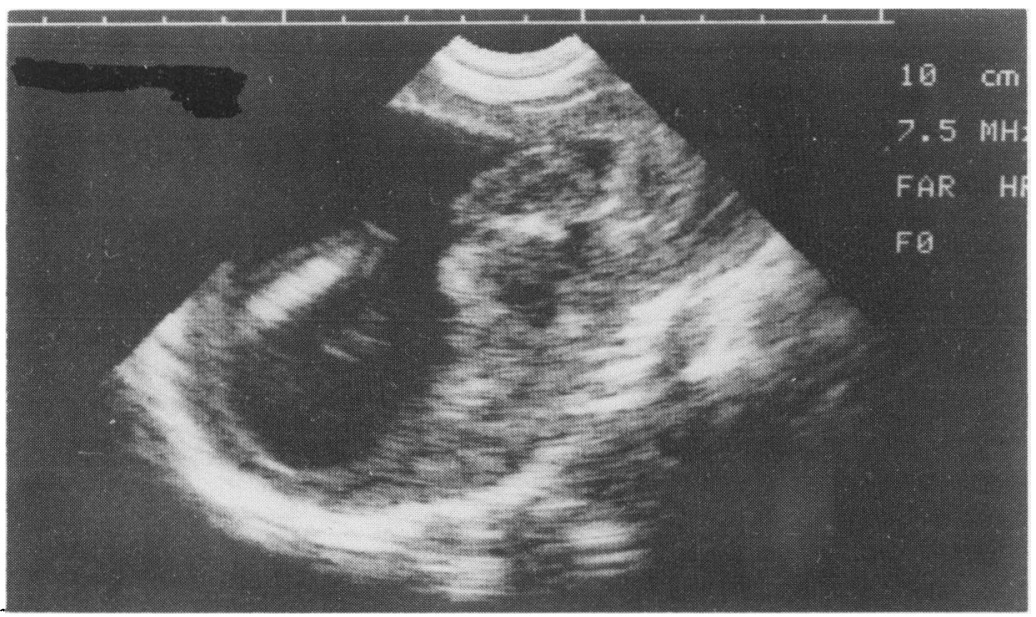

Cranial ultrasound scan (right parasaggital view) on infant 8 showing the right ventricle (posterior is to the left of the picture) with the tip of the ventricular catheter entering the occipital horn from the lambdoid suture.
Regional Health Authority. Informed consent was given by all the parents.

FIBRINOLYTIC ACTIVITY IN CEREBROSPINAL FLUID The method was an adaption of that of Astrup and Mullertz. ${ }^{9}$ Using an imidazole buffer (50 $\mathrm{mM}$ imidazole: $140 \mathrm{mM}$ sodium chloride at $\mathrm{pH}$ $7 \cdot 3$ ), a bed of fibrin agarose was made with the following final concentrations: $2.5 \mathrm{mg} / \mathrm{ml}$ human fibrinogen (KabiVitrum grade L), $0.25 \mathrm{IU} / \mathrm{ml}$ human thrombin (MRC reagent 66/305) in low gelling temperature agarose (Sigma Chemical Co) in a glass dish. After setting, holes $4 \mathrm{~mm}$ in diameter were bored out of the plate and filled with samples of cerebrospinal fluid. The plate was then incubated in a moist atmosphere at $37^{\circ} \mathrm{C}$ for 18 hours after which the fibrinolytic activity was assessed by squaring the diameter of the clear lysis zones created by the samples. The larger the lysis zone, the greater the activity.

Fibrinolytic activity in blood was monitored by serial measurements of fibrinogen levels in all cases, D-dimer analysis in two cases and the euglobulin clot lysis time in one case.

\section{Results}

All the infants have survived and only one has gone on to develop progressive hydrocephalus requiring surgical shunting (table). Infants 3,7 , and 8 had technical problems necessitating catheter removal with consequent reduction in the total dose delivered. Infant 3 developed fresh intraventricular bleeding resulting in discontinuation of the streptokinase infusion. The liquid blood was aspirated from the ventricle and, after a blood transfusion, the infant's condition stabilised. This infant did not develop progressive hydrocephalus or parenchymal cystic cerebral lesions. Infant 7 received a course of acetazolamide in addition to the streptokinase infusion.

In infant 2, fibrinolytic activity (area on the plate in $\mathrm{mm}^{2}$ ) was 480 in ventricular cerebrospinal fluid before streptokinase, 1820 in ventricular cerebrospinal fluid during streptokinase treatment, and 1550 in lumbar cerebrospinal fluid during streptokinase treatment. In no case was there any evidence of a streptokinase effect in the circulating blood as indicated by a decrease in plasma fibrinogen, increase in D-dimers, decreased euglobulin clot lysis time, or generalised bleeding tendency. No cases of cerebrospinal fluid or local infection occurred in connection with the streptokinase treatment.

Details of infants studied

\begin{tabular}{|c|c|c|c|c|c|c|c|c|}
\hline $\begin{array}{l}\text { Infant } \\
\text { No }\end{array}$ & $\begin{array}{l}\text { Birth weight } \\
(\mathrm{g})\end{array}$ & $\begin{array}{l}\text { Gestational age } \\
\text { (weeks) }\end{array}$ & $\begin{array}{l}\text { Age at } \\
\text { treatment } \\
\text { (days) }\end{array}$ & $\begin{array}{l}\text { Dose } \\
\text { (units) }\end{array}$ & Shunt & Alive & Infection & Bleeding \\
\hline $\begin{array}{l}1 \\
2 \\
3 \\
4 \\
5 \\
6 \\
7 \\
8 \\
9\end{array}$ & $\begin{array}{r}1393 \\
1298 \\
996 \\
724 \\
1016 \\
900 \\
1750 \\
1180 \\
1520\end{array}$ & $\begin{array}{l}30 \\
28 \\
27 \\
25 \\
26 \\
26 \\
31 \\
27 \\
30\end{array}$ & $\begin{array}{r}11 \\
10 \\
8 \\
13 \\
8 \\
22 \\
20 \\
22 \\
18\end{array}$ & $\begin{array}{r}70000 \\
40000 \\
7000 \\
40000 \\
40000 \\
40000 \\
38000 \\
13000 \\
40000\end{array}$ & $\begin{array}{l}\text { No } \\
\text { No } \\
\text { No } \\
\text { Yes } \\
\text { No } \\
\text { No } \\
\text { No } \\
\text { No } \\
\text { No }\end{array}$ & $\begin{array}{l}\text { Yes } \\
\text { Yes } \\
\text { Yes } \\
\text { Yes } \\
\text { Yes } \\
\text { Yes } \\
\text { Yes } \\
\text { Yes } \\
\text { Yes }\end{array}$ & $\begin{array}{l}\text { No } \\
\text { No } \\
\text { No } \\
\text { No } \\
\text { No } \\
\text { No } \\
\text { No } \\
\text { No } \\
\text { No }\end{array}$ & $\begin{array}{l}\text { No } \\
\text { No } \\
\text { Yes } \\
\text { No } \\
\text { No } \\
\text { No } \\
\text { No } \\
\text { No } \\
\text { No }\end{array}$ \\
\hline
\end{tabular}




\section{Discussion}

The percutaneous placement of a ventricular catheter via the lambdoid suture allows simultaneous viewing of the procedure by ultrasound probe on the fontanelle. Despite the highly invasive nature of the technique it can be carried out with a no-touch sterile technique. Because of the risk of staphylococcal infection and its serious consequences, we chose to treat prophylactically with both local and systemic vancomycin. No infection occurred.

The low dose and local nature of the treatment would not be expected to give a systemic fibrinolytic effect with consumption of fibrinogen and none was found. The one case of intraventricular rebleeding was easily diagnosed and effectively treated without apparent complications. The demoistration of increased fibrinolytic activity in lumbar cerebrospinal fluid during streptokinase infusion is important as it is the subarachnoid cerebrospinal fluid which bathes the likely sites where small multiple clots obstruct reabsorption of cerebrospinal fluid when the hydrocephalus is communicating. All cases in this study had communicating hydrocephalus. The lumbar puncture during ventricular streptokinase infusion may be important to try and 'draw' the streptokinase down to the sites where it needs to be active. In addition, it serves to lower pressure if the intraventricular infusion of $12 \mathrm{ml}$ per day has raised cerebrospinal fluid pressure. If necessary, normal ventricular pressure can be maintained by repeatedly withdrawing ventricular fluid.
We have shown that the techniques of streptokinase infusion can be carried out in preterm infants. On the basis of the multicentre ventriculomegaly trial, $62 \%$ (five or six infants out of nine reaching the criteria for inclusion) would have been expected to have reached surgical shunting. ${ }^{3}$ Thus the finding of only one shunt being required in the nine cases is encouraging. Further studies are needed to address questions as to optimal dosage and duration of treatment as well as safety and effectiveness of this direct therapeutic approach to the prevention of progressive posthaemorrhagic hydrocephalus and permanent shunt dependence.

De Vries LS, Larroche JC, Levene MI. Intracranial Sequelae. In: Levene MI, Bennett MJ, Punt J, eds. Fetal and neonatel neurology and neurosurgery. Edinburgh: Churchill Living stone, 1988:346-52.

2 Hislop J, Dubowitz L, Kaiser A, Singh P, Whitelaw A. Outcome of infants shunted for posthaemorrhagic ventricular dilatation. Dev Med Child Neurol 1988;30:451-6.

3 Ventriculomegaly Trial Group. Randomised trial of early tapping $\mathrm{v}$ conservative management in infants with posthaemorrhagic hydrocephalus. Arch Dis Child 1990;65:3-10.

4 Cowan F. Whitelaw A. Acute effects of acetazolamide on cerebral blood flow velocity and $\mathrm{PCO}_{2}$ in the newborn cerebral blood flow velocity and $\mathrm{pCO}_{2}$

5 Pang D, Sclabassi RJ, Horton JA. Lysis of intraventricular blood clot with urokinase in a canine model: part 3 . Neurosurgery 1986;19:553-72.

6 Newman RL, Stewart GT. The use of fibrinolytic activators in meningitis and similar conditions. Arch Dis Child in meningitis

7 Stewart GT. Fibrinolytic therapy in meningitis and ventriculitis. F Clin Pathol 1964;17:355-9.

8 Todo T, Usui M, Takakura K. Treatment of sever intraventricular hemorrhage by intraventricular infusion of urokinase. $\mathcal{F}$ Neurosurg 1991;74:81-6.

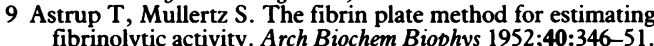

